\title{
A Comparative Study of Chinese Xiangliu and Greek Hydra
}

\author{
Huang Chi \\ School of Foreign Languages, Chengdu University of Information Technology, China
}

Received September 26, 2021; Revised November 1, 2021; Accepted November 29, 2021

\section{Cite This Paper in the following Citation Styles}

(a): [1] Huang Chi , "A Comparative Study of Chinese Xiangliu and Greek Hydra," Sociology and Anthropology, Vol. 9, No. 4, pp. 37 - 41, 2021. DOI: 10.13189/sa.2021.090401.

(b): Huang Chi (2021). A Comparative Study of Chinese Xiangliu and Greek Hydra. Sociology and Anthropology, 9(4), 37 - 41. DOI: 10.13189/sa.2021.090401.

Copyright $\odot 2021$ by authors, all rights reserved. Authors agree that this article remains permanently open access under the terms of the Creative Commons Attribution License 4.0 International License

\begin{abstract}
Mythology reflects ancient people's primitive understanding of the origin of the world, natural phenomena and social life, so the mythological narration is usually full of imagination and symbolic meanings. In both Chinese and Greek Mythology, there is a similar legend of nine-headed snakes, which reflects those ancient people's exploration of unaccountable great floods. These nine-headed monsters are called Xiangliu and Hydra respectively. According to Guideways Through Mountains and Seas, a classic collection of Chinese ancient stories, Xiangliu is the courtier of Gonggong, a legendary god of Water. Hydra in Greek mythology is a gigantic snake-like monster with nine heads, living near Lake Lerna. Both the two malicious beasts have nine heads, and are trouble-makers through taking advantage of floods, always producing poisonous smell and breath. Xiangliu has nine human faces, and his heads do not have the ability to regenerate, while Hydra has dragon-like heads with teeth and claws, and he has the ability to regenerate. Both stories are symbolic with hero-worshiping and flood-controlling themes, reflecting primitive common values in both cultures. Through comparing Xiangliu and Hydra, discussing their prototypes and their evolutionary forms in later works, we may have a better understanding of Chinese and western mythical stories, and then promote mutual respect to divergences.
\end{abstract}

Keywords Nine-Headed Snakes, Myths, Xiangliu, Hydra

\section{Introduction}

A nine-headed snake, as the name indicates, is a big snake with nine heads. Its myths or legends actually exist in many different cultures. Japanese ancient stories have the record of a nine-headed snake who would take a virgin every winter as its sacrifice. Avesta, a Persian classic about the creation of the world and the early history of the nation, records the existence of such a monster. In ancient Greek mythology, this kind of monster is called Lernaean Hydra, which lives near Lake Lerna and then is also called Lerna Hydra. The Chinese nine-headed snake is called Xiangliu in Guideways Through Mountains and Seas, a classic collection of Chinese ancient stories. Xiangliu is a courtier of Gonggong, a legendary god of Water in Chinese mythology.

This article will focus on comparing Hydra in ancient Greek mythology with Xiangliu in Chinese stories, so as to promote an intercultural communication in terms of classical stories. Both Xiangliu and Hydra have their prototypes in earlier mythological recordings, and have their evolutionary references in later literary or even historical works. Xinagliu's human-like faces and Hydra's regenerating power demonstrate people's different attitudes towards snakes, dragons, nature and human-nature relationship. Therefore, different thinking modes and moral structures between China and the west might be revealed in some way.

\section{Xiangliu in Chinese Mythology}

Xiangliu in Chinese culture has a long history. It can be 
traced back to the ancient classic Guideways Through Mountains and Seas. It also has its evolutionary forms in subsequent mythological stories, such as the nine-headed insect in Journey to the West, a world-renowned Chinese classic with the Monkey King as the central character.

\subsection{Prototype in Guideways through Mountains and Seas}

Guideways Through Mountains and Seas is noted for its integrated characteristics with diversity, complexity, compatibility and practicality. Therefore, many readers today call it an encyclopedia of ancient China. It is like a treasure bowl of motley knowledge, storing valuable information in many aspects, such as history, geography, literature, medicine, religion, painting art, folklore, myths and legends, and even miscellaneous theories.

In Guideways Through Mountains and Seas, Xiangliu was a courtier of the god of water, with human faces in nine heads, and a snake body[1]. The places where it passed or stayed would become swamps and rivers, and the smell would be pungent and bitter. No grains or vegetables could be grown, and no human beings or animals were able to survive there. Dayu, one of the most capable emperors who was as famous as Yao and Shun in ancient China, vowed to control the devastating flood caused by Xiangliu. As a partly historical and partly legendary figure, Dayu's main contributions were, for one thing, the establishment of the Xia Dynasty (2070BC--1600 BC), the first hereditary country in ancient Chinese history, which marked the beginning of the slave society; for another, the governance of the Yellow River, a surfy big river in central China. With vehement battles, Dayu finally killed Xiangliu, and the place where Xiangliu's blood flowed gave off a stench. In order to prevent people from being poisoned on the land stained with the blood of Xiangliu, Dayu dug up all the soil from the land polluted with the blood to build a platform for the emperors so as to strengthen their authority at the Yellow River basin. In that way, Dayu completed his great achievement of controlling the water monster and the Yellow River.

\subsection{Evolutionary Form in Journey to the West}

According to the 63rd chapter of Journey to the West, Wansheng, the Dragon King of Bibo Lake married his daughter to a nine-headed insect, or nine-headed bird. This monster was about 4 meters long, with nine heads joining together and two toes as sharp as hooks [2]. He was very good at flying with giant wings, and the sound he produced would shake the sky. His eyes are shining with golden light, showing off his extraordinary arrogance. From the apparent description of the monster, it is hard to see the connection between the nine-headed insect with Xiangliu, the nine-headed snake. However, as the story progresses, readers can get to know that this monster is actually a transformed nine-headed snake.

Chapter 63 of Journey to the West mainly tells the adventures of Sun Wukong (Monkey King), Zhu Bajie (Pigsy), and Sha Wujing (Friar Sand) and their master Xuan Zang in a fresh land called Jisai. It is said in this foreign land, one midnight three years ago, there came bloody rain. During the terrible rainstorm, the Buddhist treasure relics in Jin Guang temple were stolen. All the monks were suspected of stealing, and all the people were frightened and the whole country was immersed in suspicion and despair. Finally, after discovering that it was the nine-headed insect who had stolen the Buddhist treasure and caused the bloody rain, Monkey King tried to challenge the monster. In the end, with the help of the god Erlang, Monkey King successfully got the Buddhist treasure back to the temple, and the nine-headed insect escaped in pain and threw himself away into the North Sea. And then tranquility and order restored in the land. From the escape route of the nine-headed insect and its final whereabouts, readers can see that its obvious relation with Xiangliu. Xiangliu's blood is very stinky, making people suffer a lot with the surrounding land uninhabitable. In Journey to the West, the nine-headed insect caused a bloody rainstorm, resulting in the widespread fear and sorrow of the inhabitants, which showed the similar evil power of the monster. In the end, because of being defeated by the Monkey King, the nine-headed insect cast himself to the North Sea, where Xiangliu once lived.

The fifth chapter of Unofficial History of Xia and Shang records that Gonggong was killed by the Yellow Emperor, and Xiangliu finally fled to the North Sea[3]. Based on this, it is believable that the prototype of the nine-headed insect in Journey to the West is Xiangliu, the nine-headed snake, who fled to inhabit in the North Sea. As far as the novel Journey to the West is concerned, the author Wu Cheng'en enriches, revises and improves the folk tales, and even re-creates this artistic image of a nine-headed insect. Of course, it is full of collective wisdom of the folk literature. The metaphors of the story of the nine-headed insect can also well prove its inheritance in the myth of Xiangliu. Some Chinese scholars directly pointed out that the prototype of the nine-headed insect was Xiangliu, a troublemaker with water [4].

\section{Hydra in Greek Mythology}

\subsection{Prototype of Hydra}

Hydra in Greek mythology is the offspring of Typhon and Echidna, Gaia's children. $\mathrm{He}$ is a gigantic water-snake-like monster with nine heads (the number varies in different versions), the middle of which is immortal. The monster's place of residence was the 
marshes of Lerna, near Árgos, from which he frequently emerged to harry the people and livestock of Lerna. Anyone who attempted to behead Hydra found that as soon as one of his heads was cut off, two more heads would emerge from the fresh wound [5].

Hydra was extremely poisonous, and it would spit out so powerful venom that the gas it exhaled was also lethal. The destruction of Hydra became one of the 12 Labors of Heracles, one of the greatest heroes in Greek mythology. For that and other labors, Heracles enlisted the aid of his nephew Iolaus. As Heracles chopped off each mortal head of Hydra, Iolaus would burn the wounded neck with fire, making it impossible to regenerate. Finally, when only the immortal head remained, Heracles cut it off forcefully and buried it under a heavy rock. After the death of Hydra, Hercules quenched his arrows with the beast's poisonous blood (or venom) to make them inflict fatal wounds to his enemies. Since then, anyone who was hit by the arrows would undoubtedly die.

\subsection{Hydra in Other Works}

A lot of later literary works are also used Hydra to symbolize evil and terror. For example, John Milton [6] describes the situation of the hell in his Paradise Lost, “...Nature breeds, Where all life dies, death lives, and nature breeds/ Perverse, all monstrous, all prodigious things/ Abominable, unutterable, and worse/ Than fables yet have feign'd, or fear conceived./ Gorgons, and Hydras, and Chimeras dire." The horrible hell is presented all extremely hideous, weird, and disgusting, especially with reference to terrible snake-headed Gorgons, nine-headed Hydra and the flame-breathing monster Chimera. When the negative adjectives are used together with the three terrifying monsters, readers might have a better and intuitive understanding of the eerie, uncanny hell.

Because Hydra is so ghastly, so difficult to deal with, it is employed to refer to something tricky and complicated, or a disaster that is tough to get rid of. For example, it is often used to describe revolutionary riots. In The Many-headed Hydra: Sailors, Slaves, Commoners, and the Hidden History of the Revolutionary Atlantic, the author writes that the rulers of colonial expansion in the 17th century used "Hercules-Hydra myth" to describe the difficulty in establishing order in the increasing globalized labor system. They called the expelled civilians, exiled felons, urban laborers, soldiers, sailors and African slaves "the numerous, ever-changing heads of the monster" [7] because those people rebelled, went on strike, revolted, and launched revolutions.

In addition, Hydra also exists in some popular American Marvel movies. Members of an evil terrorist organization uphold the creed "If they cut off one head, two more shall take its place."[8] This vividly reflects the regeneration ability of the nine-headed Hydra.

\section{Similarities and Differences between Chinese Xiangliu and Greek Hydra}

The images of Chinese Xiangliu and Greek Hydra have changed in their respective lands, but many of their inherent attributes are still preserved. This section will compare their similarities and differences in order that the readers might have a better understanding of their cultural connotations so as to achieve better intercultural communication.

It can be seen from the mythology that Xiangliu and Hydra share some similar characteristics. First of all, both of them have nine heads in appearance. It is no surprise that monsters with more heads are regarded as more powerful and magical ones. "Nine" is the largest single digit, which often means the most, or the limit. We can find some Chinese idioms with the number "nine" like Jiuxiaoyunwai (九霄云外 ), which means “being very far away”, and Jiuquanzhixia (九泉之下 ) , meaning “in the nether world". Since Chinese "nine" pronounces similar to "Jiu(久)", another Chinese word which means longevity and stability, powerful ancient Chinese emperors had their "nine-dragoned costume"( 九龙袍 )[9]. In the West, “nine" is also often used to indicate a large number or a large degree. For instance, the proverb "A cat has nine lives" is used to imply that a cat is more tenacious and persistent than many other animals. People always think that due to the speed, smartness and flexibility of cats, they can stay alive in most difficult situations when other animals would have been killed. The phrase "nine times out of ten" means occurring on average nine times for every ten instances of something, or showing great possibilities. Secondly, both Xiangliu and Hydra are monsters related to floods, living near the water. In Chinese mythology, Xiangliu is a courtier, or subordinate of the water god Gonggong. The places he touches will turn to be marshes, or swamps. After his death, his inhabiting land is full of water and can never be inhabited by common people. The name of Hydra originates from the Greek word "hydor", meaning water, corresponding to the fact that Hydra lives in the marshes of Lerna. Thirdly, the smell and blood of both Xiangliu and Hydra are poisonous. Xiangliu has a fierce smell, leaving birds and beasts unable to get close. After death, his blood immerses in the ground, producing very foul smell, which makes the land uninhabitable. Hydra can emit very poisonous breath, and its blood is used even by Hercules to make lethal arrows. Both the well-known Centaur Chiron and Hercules himself die from the poisoned arrows in Greek mythology. In addition, both Xiangliu and Hydra are malicious beasts. Xiangliu mutilates the living things of the mountains nearby and pollutes the soil of the surrounding mountains. Hydra also harasses humans and the livestock. With Xiangliu being wiped out by Dayu and Hydra being decapitated by Hercules, both are subdued by great heroes.

On the other hand, there are also some obvious 
differences between Xiangliu and Hydra. Xiangliu has nine human faces, and although there is not many descriptions of Hydra's face, it can be seen from many western paintings that he appears like an evil dragon with teeth and claws. Dragon is considered in China a sacred and auspicious animal, while the snake is a symbol of wickedness. That is why Xiangliu cannot have the attributes of a dragon while Hydra has. As a hideous monster with human-like faces, Xiangliu's final failure indicates a kind of compromise of humans and nature. Unlike China, the west emphasizes individual power over nature. Hercules' victory over Hydra with ugly dragon-like faces is a good example of human conquest of nature.

Another striking difference is that Xiangliu's heads do not have the ability to regenerate, while Hydra has. Snakes can shed their skins and hibernate, which was considered by the ancestors to be periodic regeneration. The image of snakes with the ability to regenerate exists in both Chinese and Western folklore. Chinese classic Book of Changes records that both dragons and snakes hibernate in order to survive for the next year. The resurrection of Hydra's mortal heads is an example to show his regeneration ability. The fact that the heads of Xiangliu cannot be resurrected might demonstrate his human characteristics. Although Xiangliu was in the shape of a snake, his human faces determined that he could not enjoy resurrection. Hydra was born of a monster, a natural thing, therefore, it can be inferred that his resurrected heads are his natural attributes.

\section{Metaphorical Motifs Reflected through Xiangliu and Hydra}

The mythological stories of Xiangliu and Hydra present some similar metaphorical themes like hero-worshiping and flood-controlling.

\subsection{Hero Worshiping}

One of the obvious similarities of Xiangliu and Hydra is that they are poisonous. They cause harm to humans, and ordinary people are often driven into dire trouble until some heroes come to help. Dayu and Hercules are such heroes. The more terrifying the monster is, the more glorious the victory is; the more the beast struggles, the more the hero demonstrates his strength. The failure of Xiangliu and Hydra reflects the strength and loftiness of Dayu and Hercules, which demonstrates people's worship of heroes. This kind of worship comes from taking heroes as the highest moral example of a nation, and hoping to get close to heroes in order to gain strength to improve the living environment. At the same time, the perseverance and unyielding spirit of heroes encourage their followers to fight against any difficulties at any cost. Therefore, the opposition between heroes and monsters also reflects the struggle between humans and natural disasters. Disasters cause social chaos, and human resistance will lead to restoration and reconstruction of social order.

A recurring motif of dragon-slaying shows the similar storyline in Western myths. The dragon is a symbol of violence and wickedness. They are often looters, occupiers, and guards. For example, in Greek mythology, the golden fleece that Jason wanted to steel was guarded by a fire dragon, and the golden apple that Hercules wanted to take was guarded by Ladon, a hundred-headed dragon. And it was exactly Hercules who also killed Hydra, the nine-headed snake, a mini-version of the wicked dragon. In England's national epic Beowulf, the hero Beowulf sought the fire dragon which had been guarding valuable treasure in his cavern and slew the monster after a terrible fight. During the French Revolution, the Jacobins considered the revolutionary republic's victory over the corrupted federalism as the hero Hercules' stepping on Hydra[10]. The Greek word "drakōn" for dragon was originally used to refer to huge sea snakes, so the killing of Hydra can be traced back to the dragon slaying motif.

To sum up, the presentation of the stories of Xiangliu and Hydra lies not only in showing the monsters' cruelty and wickedness, but also in expressing the courage of the heroes and their desire or their ability to rebuild social order in fighting against the monsters.

\subsection{Flood Controlling}

In ancient Chinese and Greek myths, there often emerge weird snakes and vicious birds, and their appearances keep the elements of natural creatures. They are not only weird and ugly, but they often do harm to humans. This reflects ancient people's common worries before natural disasters, so the stories carry the collective memory of people's pain before natural disasters in ancient times. Because the essential feature of Xiangliu and Hydra is related to water, the heroes' elimination of evil can also be regarded as an allegory for the treatment of floods, a natural disaster.

Chinese Dayu's killing of Xiangliu is part of his water control myth, which undoubtedly reflects the water control activities of the Chinese ancestors. Dayu's flood controlling image is seen in later literary works. For example, Dayu can be considered as the archetype of Monkey King in the world-known Chinese classic Journey to the West. According to Huai Nan Zi, a Chinese philosophical and legendary book in West Han Dynasty, Dayu was born out of stone. When he was ordered by Shun, his predecessor, to control flood, he tried his best and dedicated to this holy business. Like Dayu, Monkey King was also born out of a mysterious stone. In the 63rd chapter of Journey to the West, Monkey King worked together with god Erlang to kill a nine-headed insect, 
which could be regarded as a metaphor of flood controlling by heroes, since the nine-headed beast carries the inherent image of Xiangliu. One saying of the origin of god Erlang is that he was Li Erlang, Li Bing's second son, who assisted his father in killing an evil dragon to quell the flood. Li Bing was a famous water conservancy engineer in the Warring States(475BC--221BC) in Chinese history, who was especially noted for his harnessing the overflowing rivers in Sichuan.

The elimination of Hydra by Hercules in Greek mythology can be interpreted as a collective memory of the drainage project in the area, aiming at alleviating the threat of water. Some scholars pointed out that Hydra might symbolize the karstic water in the area or the Lerna swamp itself, and the destruction of Hydra by Hercules might be explained as the drying up of the swamp [11]. The feature of Hydra's resurrecting heads is believed to be the overflowing streams while the running flood is blocked. A Chinese saying goes that "a big river is divided into nine streams", therefore, it can be considered an artistic expression to regard Xiangliu's nine heads as the diversions of floods. In addition, Hercules's battle with the river-god Acheloos in Greek mythology can reflect humans' efforts to control the destructive flood.

\section{Conclusion}

Myths reflect ancient people's primitive thoughts about the world, natural phenomena and social life. The myths of Xiangliu and Hydra are important parts of Chinese and Greek mythology respectively, and both have influenced many later literary works. By comparing the images of these two, discovering the similarities and differences, exploring the metaphorical themes behind them, we may have a better understanding of both Chinese and western culture, moral values, and thinking modes, and then hopefully promote more sound mutual relations.

\section{Acknowledgements}

The article is an achievement of the project
"Intercultural Communication of China and the West" (BKJX2020067) supported by Undergraduate Teaching Fund Projects in Chengdu University of Information Technology. I am quite grateful for the fund to enable me to conduct this research.

\section{REFERENCES}

[1] Richard E. Strassberg, "A Chinese Bestiary: Guideways Through Mountains and Seas", University of California Press, 2018.

[2] Wu Cheng'en, "Journey to the West", Jilin Publishing Group Co., Ltd. 2012.

[3] Zhong Xing, "Unofficial History of Xia and Shang Dynasties", Zhejiang Publishing Group Digital Media Co., Ltd., 2020.

[4] Zhao Yichao, "Looking at the Image of Monkey King from the Nine-head Insect and the Myth of Dayu", Journal of Yanbian College of Education, 2020, Vol.34, no.1, pp. 20-23. DOI:10.3969/j.issn.1673-4564.2020.01.007

[5] Schwab Gustav, "Ancient Greek Myths and Legends", China Friendship Publishing Company, 2019.

[6] John Milton, "Paradise Lost", W.W. Norton \& Company, Inc., 2020.

[7] Peter Linebaugh, Rediker Marcus, "The Many-headed Hydra: Sailors, Slaves, Commoners, and the Hidden History of the Revolutionary Atlantic", Verso, 2000.

[8] Bawangzhilu, "Captain America: an Appreciation of an American movie", https://baijiahao.baidu.com/s?id=16209 70090599593360. (accessed May 9, 2001)

[9] Wang Hui, "Chinese Culture and Intercultural Communication”, Commercial Press, 2017, p.143.

[10] Lynn Hunt. "Politics, Culture, and Class in the French Revolution: With a New Preface", University of California Press, 2004, pp.95-98.

[11] Koutsoyiannis, Demetris, A.N. Angelakis. "Agricultural Hydraulic Works in Ancient Greece", The Encyclopedia of Water Science, 2004, pp. 415-417. 